\title{
Correction to: Protective effects of amifostine, curcumin and melatonin against cisplatin-induced acute kidney injury
}

Filiz Mercantepe ${ }^{1} \cdot$ Tolga Mercantepe $^{2} \cdot$ Atilla Topcu $^{3} \cdot$ Adnan Yilmaz $^{4} \cdot$ Levent Tumkaya $^{2}$

Published online: 1 March 2019

(C) Springer-Verlag GmbH Germany, part of Springer Nature 2019

\section{Correction to: Naunyn Schmiedebergs Arch Pharmacol. 2018 Sep;391(9):915-931 \\ https://doi.org//10.1007/s00210-018-1514-4}

Due to an oversight, Drug treatment (Material and Methods section) in Mercantepe et al. (2018) Naunyn Schmiedebergs Arch Pharmacol. 2018 Sep;391(9):915-931. doi: https://doi. org/10.1007/s00210-018-1514-4.

\section{Materials and Methods}

\subsection{Drug treatment}

The Cis+AMF group (Group 3) in our study received a single $200 \mathrm{mg} / \mathrm{kg}$ IP dose of AMF thirty minutes before Cis administration (Er-Kim İlaç Sanayi ve Tic. A.Ș., Beşiktaş, Turkey) (Uzunoglu et al. 2011; Mercantepe et al. 2018a).

Publisher's note Springer Nature remains neutral with regard to jurisdictional claims in published maps and institutional affiliations.

The online version of the original article can be found at https://doi.org/ $10.1007 / \mathrm{s} 00210-018-1514-4$

Filiz Mercantepe

filizmercantepe@hotmail.com

1 Department of Internal Medicine, Faculty of Medicine, Recep Tayyip Erdogan University, Islampaşa Mahallesi, Iki numaralı Sehitler Caddesi, No: 74, 53010 Rize, Turkey

2 Department of Histology and Embryology, Faculty of Medicine, Recep Tayyip Erdogan University, 53010 Rize, Turkey

3 Department of Pharmacology, Faculty of Medicine, Recep Tayyip Erdogan University, 53010 Rize, Turkey

4 Department of Biochemistry, Faculty of Medicine, Recep Tayyip Erdogan University, 53010 Rize, Turkey 